\title{
Assessment of Radiation Doses for Lungs due to Some Radionuclides Released from a Hypothetical Nuclear Power Reactor Accident
}

\author{
${ }^{1}$ Md Moniruzzaman Khan, ${ }^{2}$ A.H.M. Ruhul Quddus, ${ }^{3}$ Mir Md Akramuzzaman, ${ }^{4}$ Abdus Sattar Mollah \\ ${ }^{1}$ Army Education Corps, Bangladesh Army, ${ }^{2}$ National University, Bangladesh \\ ${ }^{3}$ Physics Department, Jahangirnagar University, Savar, Dhaka, Bangladesh \\ ${ }^{4}$ Bangladesh Atomic Energy Commission, Agargaon, Dhaka, Bangladesh \\ Correspondence: Md Moniruzzaman Khan, e-mail: mzaman5769@gmail.com
}

\begin{abstract}
Different radionuclides are emitted from the reactor core after the nuclear accident. These radionuclides are entered into human body through different pathways, which damage the cells. The dose consequence to the sensitive organ like lungs of human body is considered in the present study to show the dose effect for various radionuclides from a hypothetical nuclear reactor accident. The calculations were made with the in-house developed computer program "RaDARRA". Cardinal directions like E, ENE, ESE, N, NE, NNE, NNW, NW, S, SE, SSE, SSW, SW, W, WNW and WSW are considered to observe the dose effect along the directions. For the calculations, lungs dose arising from 8 radionuclides e.g., ${ }^{89} \mathrm{Sr},{ }^{91} \mathrm{Y},{ }^{95} \mathrm{Zr}$, ${ }^{95} \mathrm{Nb},{ }^{131} \mathrm{I},{ }^{133} \mathrm{I},{ }^{140} \mathrm{Ba}$ and ${ }^{144} \mathrm{Ce}$ have been considered. Of all these radionuclides the maximum and minimum dose contribution mainly come from ${ }^{144} \mathrm{Ce}(30 \%)$ and ${ }^{95} \mathrm{Nb}(4.43 \%)$. It is marked that dose is maximum along North East (NE) direction for all the distances and for all types of the radioisotopes. Methodology used in the present study can also be utilized for any type of severe accident and any type of reactor power.

Key words: Radiation doses, lungs, radionuclides, accident, power, reactor, and radiation protection
\end{abstract}

\section{INTRODUCTION}

Severe accidents involve very complex physicochemical and radiological phenomena that take place during various stages of the power reactor accident. These phenomena and the associated severe accident phases are typically divided into two groups. Of these the invessel phase covers core heat-up, fuel degradation and material relocation expected to occur inside the reactor pressure vessel up to the failure of the reactor pressure vessel, and subsequent release of molten corium into the containment building. The ex-vessel phase covers thermal and chemical interactions between core debris and containment structures, and containment behavior including transport of radioactive substances. 
When reactor temperature is $1000^{\circ} \mathrm{K}$ or above the $\mathrm{Zr}$ cladding may be weak, ballooned, and ruptured. This may result in the damage of fuel rods in the power burst facility. Consequently some volatile fission products like I, Ba, Ce etc. may be released. The volatile materials would diffuse out of the hot fuel and would be released as vapors. Once inert gas falls out the other radionuclides undergo chemical interactions among themselves. Some source terms like aerosols may thus be formed. If reactor coolant system boundary breaks, some of the transported radioactive materials may be released instantly as gas and aerosol along with the steam, hydrogen, and reactor coolant. The aerosols tend to increase in size by agglomeration processes in containment or inside the reactor coolant system. These aerosols would be settled due to transportation towards the surfaces of the reactor containment through diffusion, temperature differences, and other processes. The amount of aerosols exists depend upon their generation rate as well as their removal rate.

Severe accidents, and specifically their analyses, are addressed in a number of IAEA publications (1-2). Severe accident research began in the 1970s with early fuel rod melting experiments, resulting in the development of an extensive experimental database. The results of such research programs have been summarized in a variety of publications (3-4). Other suggested references for relevant European Union programs are included in literature (5-6). The main purpose of present work is to calculate the lungs doses due to different radionuclides escaping from a hypothetical nuclear power reactor accident.

\section{METHODS}

In the present calculation, point source dispersion parameters are considered because this type of source is a single, identifiable source of air pollutant emissions which commensurate with the present accidental case. Point sources are also characterized for its elevated position or for being at ground level.

\section{Core Inventory}

The reactor core inventory is a function of fissile materials, fission yield, release fraction, type of reactor, reactor power etc. Various mathematical expressions can be implemented to calculate the amount of fission products in the nuclear reaction core as a function of irradiation time. An approximate formula giving activity, $\mathrm{q}_{\mathrm{i}}(\mathrm{t})$, of an isotope $\mathrm{i}$ at time $\mathrm{t}$ after the start of irradiation $(\mathrm{t}=0)$ whose fission yield is $\gamma_{\mathrm{i}}$ and its decay constant is $\lambda$ 
irradiated for time period $\mathrm{T}$ in $\mathrm{P}$ (megawatts of thermal power) can be obtained (7) from the equation 1.

$$
\mathrm{q}_{\mathrm{i}}=0.84 \gamma_{\mathrm{i}} \mathrm{P}\left(1-\mathrm{e}^{-\lambda \mathrm{T}}\right)
$$

Here $\mathrm{q}_{\mathrm{i}}$ is the amount of isotope $\mathrm{i}$ contained in the fuel after irradiation time $\mathrm{T}$ in $\mathrm{Bq} ; \mathrm{P}$ is the fuel power level in watts; $\gamma_{i}$ is the fission yield of isotope $i ; \lambda$ is the radiological decay constant for the isotope in $\mathrm{s}^{-1}$; and $\mathrm{T}$ is the time interval during which the fuel has been at power $\mathrm{P}$ in s. In many safety analysis reports (SARs), the core inventory of the fission products is formulated based on equation 1. To find the core inventory, anumber of radionuclides are chosen considering their radiological effect to human bodies.

\section{Release Activity and Leakage Rates}

The total activity or source term or release rate of isotope $i$ released over time $t, Q_{i}(t)$, is obtained [7] from the equation 2.

$$
Q_{i}(t)=F_{p} F_{b} q_{i}(t) \frac{\lambda_{l}}{\lambda_{l}+\lambda_{r}}\left[1-e^{-\left(\lambda_{l}+\lambda_{r}\right) t}\right]
$$

Where, $F_{P}$ is fractional release from fuel to building, $F_{B}$ is fraction remaining airborne and available to be released from the building to the atmosphere, $\mathrm{q}_{\mathrm{i}}$ is core inventory in $\mathrm{Bq}, \lambda_{\ell}$ is leakage rate parameter in $\sec ^{-1}$, and $\lambda_{r}$ is radioactive decay constant in $\sec ^{-1}, \mathrm{t}$ is time after accident in sec.

Release rates of isotopes depend on reactor fission product inventory, paths and rates of leakage from the primary system to the containment, and also from the containment or reactor building to the atmosphere. The leakage rates depend strongly on system design and containment or reactor building design. In addition, the leak fraction of a given radionuclide depends on its chemical form. The inventory of fission product of various radionuclides required for this calculation for 300 days irradiation time and $1000 \mathrm{MW}$ power is obtained from equation 1.

\section{Ground Level Concentration}

From any radial distance $x$ from the release point, the maximum ground level $(z=0)$ timeintegrated concentration directly downwind occurs beneath the centre line $(y=0)$ of the cloud. The time-integrated concentration at off-centerline position is obtained from the equation 3.

$$
\chi(x)=\frac{Q}{\pi \cdot \sigma_{y} \cdot \sigma_{z} \cdot u_{x}} \exp \left\{\frac{-H^{2}}{2 \sigma_{z}^{2}}\right\} \quad \mathrm{Bq}-\mathrm{sec} / \mathrm{m}^{3}
$$

or, 


$$
\chi^{/} Q=\frac{1}{\pi \sigma_{y} \sigma_{z} u} \exp \left[-\frac{1}{2}\left(\frac{H}{\sigma_{z}}\right)^{2}\right] \quad \mathrm{Sec} / \mathrm{m}^{3}
$$

The quantity $\chi / \mathrm{Q}$ is called as centerline or atmospheric diffusion factor $\left(\mathrm{s} / \mathrm{m}^{3}\right)$. Applying the above equation, the average concentration and dose for release that occur over an extended period of time can be calculated.

\section{Dose Calculation for Radionuclides Released}

During the overhead passage of the plume, a person standing on the ground is expected to inhale an amount of radioactive material proportional to the passage time and the concentration at the location in question. The total internal dose integrated over a given period of time after the activity was inhaled to organ $\mathrm{k}$ from isotope $\mathrm{i}$ can be expressed as:

$$
D_{i}^{k}=[\chi / Q(t)] Q_{i}(t) \cdot B R(t) \cdot D C F_{i}^{k}
$$

Here $\chi / \mathrm{Q}(\mathrm{t})$ is the atmospheric diffusion factor in $\mathrm{s} / \mathrm{m}^{3}, \mathrm{Q}_{\mathrm{i}}(\mathrm{t})$ is the release activity of isotope $\mathrm{i}$ released over time $\mathrm{t}$ in $\mathrm{Bq}, \mathrm{BR}(\mathrm{t})$ is the breathing rate for a $60 \mathrm{~kg}$ Bangladeshi male receptor during the time $\mathrm{t}$ in $\mathrm{m}^{3} / \mathrm{s}$ and $D C F_{i}{ }^{k}$ is the dose conversion factor for organ $\mathrm{k}$ and isotope $\mathrm{i}$ in $\mathrm{Sv} / \mathrm{Bq}$. The dose-conversion factor for a given radionuclide is equal to the dose per unit intake ( $\mathrm{Sv} / \mathrm{Bq})$ integrated over a given period of time after the intake. Table1 shows the dose conversion factors of the relevant radionuclides for internal whole body dose for lungs (7).

Table 1. Dose conversion factors (DCF) for the radionuclides considered Breathing Rate Data

\begin{tabular}{|c|c|c|c|}
\hline $\begin{array}{c}\text { Type of } \\
\text { Radionuclides }\end{array}$ & $\begin{array}{c}\text { DCF for lung } \\
\mathrm{Sv} / \mathrm{Bq}\end{array}$ & $\begin{array}{c}\text { Type of } \\
\text { Radionuclides }\end{array}$ & $\begin{array}{c}\text { DCF for lung } \\
\mathrm{Sv} / \mathrm{Bq}\end{array}$ \\
\hline${ }^{89} \mathrm{Sr}$ & $4.83 \times 10^{-8}$ & ${ }^{131} \mathrm{I}$ & $5.59 \times 10^{-9}$ \\
\hline${ }^{91} \mathrm{Y}$ & $5.70 \times 10^{-8}$ & ${ }^{133} \mathrm{I}$ & $1.37 \times 10^{-9}$ \\
\hline${ }^{95} \mathrm{Zr}$ & $5.32 \times 10^{-8}$ & ${ }^{140} \mathrm{Ba}$ & $4.00 \times 10^{-8}$ \\
\hline${ }^{95} \mathrm{Nb}$ & $1.74 \times 10^{-8}$ & ${ }^{144} \mathrm{Ce}$ & $4.00 \times 10^{-8}$ \\
\hline
\end{tabular}

For the calculation of inhalation doses the breathing rate of the receptor during the time of exposure is to be specified. The breathing rate data for man/women in these analyses are taken from USNRC Regulatory Guides 1.3 (8). The rate, as considered here is for a person of average weight $60 \mathrm{~kg}$ of Bangladeshi origin. The first 8 hours of the exposure are taken to be an active period with a breathing rate of $2.60 \times 10^{-4} \mathrm{~m}^{3} / \mathrm{s}$. The interval from $8-24$ hours is considered to be a resting period with a rate of $1.31 \times 10^{-4} \mathrm{~m}^{3} / \mathrm{s}$. For time periods greater than one day, a breathing rate of $1.74 \times 10^{-4} \mathrm{~m}^{3} / \mathrm{s}$ is used. In the present study breathing rate greater than 1 day has only been considered. 


\section{RESULTS AND DISCUSSION}

Core inventory values for $1000 \mathrm{MW}$ power reactor are calculated for irradiation time of 200, 300 and 400 days and shown in Table 2. It has been observed that if number of days increase then core inventory also increases. This occurs because core inventory is directly proportional to fission yield. Among eight radionuclides that have been considered in the present study, it is observed that maximum value is $20.8 \times 10^{17} \mathrm{~Bq}$ for ${ }^{133} \mathrm{I}$ and minimum is $8.7 \times 10^{17} \mathrm{~Bq}$ for ${ }^{131} \mathrm{I}$. The inequality can be expressed as:

$$
{ }^{133} \mathrm{I}>{ }^{95} \mathrm{Nb}>{ }^{95} \mathrm{Zr}>{ }^{140} \mathrm{Ba}>{ }^{91} \mathrm{Y}>{ }^{89} \mathrm{Sr}>{ }^{144} \mathrm{Ce}>{ }^{131} \mathrm{I}
$$

Table 2. Core inventory for $1000 \mathrm{MW}$ power reactor (varying irradiation time)

\begin{tabular}{|c|l|c|c|c|}
\hline \multirow{2}{*}{ Radionuclides } & \multirow{2}{*}{$\begin{array}{c}\text { Decay constant } \\
\text { (per day) }\end{array}$} & \multicolumn{3}{|c|}{ Core inventory, $\mathrm{q}_{\mathrm{i}}\left(\mathrm{Bq} \times 10^{17}\right)$} \\
\cline { 3 - 5 } & & 200 days & 300 days & 400 days \\
\hline${ }^{89} \mathrm{Sr}$ & $1.38 \times 10^{-2}$ & 14.0 & 14.7 & 14.9 \\
\hline${ }^{91} \mathrm{Y}$ & $1.47 \times 10^{-2}$ & 17.4 & 18.1 & 18.3 \\
\hline${ }^{95} \mathrm{Zr}$ & $1.04 \times 10^{-2}$ & 17.6 & 19.3 & 19.9 \\
\hline${ }^{95} \mathrm{Nb}$ & $1.99 \times 10^{-2}$ & 19.8 & 20.2 & 20.2 \\
\hline${ }^{131} \mathrm{I}$ & $8.60 \times 10^{-2}$ & 8.7 & 8.7 & 8.7 \\
\hline${ }^{133} \mathrm{I}$ & $8.04 \times 10^{-1}$ & 20.8 & 20.8 & 20.8 \\
\hline${ }^{140} \mathrm{Ba}$ & $5.44 \times 10^{-2}$ & 19.3 & 19.3 & 19.3 \\
\hline${ }^{144} \mathrm{Ce}$ & $2.44 \times 10^{-3}$ & 6.46 & 8.69 & 10.4 \\
\hline
\end{tabular}

The source strength for 1 day, 7 days and 1 month after the accident is taken (Table 3 ) to calculate the doses using Eqn. 2. Like core inventory it has also been observed that values of source strength increase as number of days increases. The inequality of the values of source strength can be shown as:

$$
{ }^{131} \mathrm{I}>{ }^{133} \mathrm{I}>{ }^{95} \mathrm{Zr}>{ }^{95} \mathrm{Nb}>{ }^{91} \mathrm{Y}>{ }^{89} \mathrm{Sr}>{ }^{140} \mathrm{Ba}>{ }^{144} \mathrm{Ce}
$$


Table 3. Source strength values for the radionuclides considered for varying time

\begin{tabular}{|c|c|c|c|c|}
\hline \multirow{2}{*}{ Radionuclides } & \multirow{2}{*}{$\begin{array}{c}\text { Decay } \\
\text { constant } \\
\text { (per sec) }\end{array}$} & \multicolumn{3}{|c|}{ Source strength, $\mathrm{Q}_{i}(\mathrm{~Bq})$} \\
\cline { 3 - 5 } & $1.60 \times 10^{-7}$ & $1.46 \times 10^{14}$ & $9.93 \times 10^{14}$ & $3.81 \times 10^{15}$ \\
\hline${ }^{89} \mathrm{Sr}$ & $1.7 \times 10^{-7}$ & $1.79 \times 10^{14}$ & $1.16 \times 10^{15}$ & $3.83 \times 10^{15}$ \\
\hline${ }^{91} \mathrm{Y}$ & $1.20 \times 10^{-7}$ & $1.91 \times 10^{14}$ & $1.26 \times 10^{15}$ & $4.33 \times 10^{15}$ \\
\hline${ }^{95} \mathrm{Zr}$ & $2.3 \times 10^{-7}$ & $1.99 \times 10^{14}$ & $1.28 \times 10^{15}$ & $4.0 \times 10^{15}$ \\
\hline${ }^{95} \mathrm{Nb}$ & $9.95 \times 10^{-7}$ & $2.07 \times 10^{15}$ & $11.1 \times 10^{15}$ & $21.3 \times 10^{15}$ \\
\hline${ }^{131} \mathrm{I}$ & $9.3 \times 10^{-6}$ & $3.56 \times 10^{15}$ & $6.37 \times 10^{15}$ & $6.39 \times 10^{15}$ \\
\hline${ }^{133} \mathrm{I}$ & $6.3 \times 10^{-7}$ & $1.87 \times 10^{14}$ & $1.09 \times 10^{15}$ & $2.56 \times 10^{15}$ \\
\hline${ }^{140} \mathrm{Ba}$ & $2.82 \times 10^{-8}$ & $8.63 \times 10^{13}$ & $5.82 \times 10^{14}$ & $2.18 \times 10^{15}$ \\
\hline${ }^{144} \mathrm{Ce}$ & & & & \\
\hline
\end{tabular}

For calculation of different parameters for equations 1-5, a computer programme "RaDARRA" has been developed based on visual basic language (9). The dose levels for different distances are calculated by using equations 3 and 5. The details procedures are described elsewhere (9). Lung, being very sensitive organ, is badly affected by the radiation if any nearby power reactor falls under accident. Radiological doses on this organ are calculated considering the distance variation from $0.5 \mathrm{~km}$ up to $5 \mathrm{~km}$ while keeping the breathing rate unchanged. In total 8 prominent radionuclides are considered for the calculation of internal dose in the lungs. Dose variation for different distances follows the same serial given below along the 16 cardinal directions:

$\mathrm{NE}>\mathrm{N}>\mathrm{NW}>\mathrm{ENE}>\mathrm{NNW}>\mathrm{SW}>\mathrm{SE}>\mathrm{W}>\mathrm{NNE}>\mathrm{S}>\mathrm{WNW}>\mathrm{E}>\mathrm{WSW}>\mathrm{SSW}>\mathrm{SSE}>\mathrm{ESE}$

Calculated values of the doses from these isotopes are shown in Figures 1 and 2. Maximum dose values are found along NE direction.

Values of dose from ${ }^{89} \mathrm{Sr}$ show that it is harmful for human health up to a distance little more than 1 $\mathrm{km}$. Of course, dose values from the radionuclides ${ }^{91} \mathrm{Y}$ and ${ }^{95} \mathrm{Zr}$ show enough similarity (Figure. 1). For both the cases radiation sustains in danger limit up to the distance of $2 \mathrm{~km}$. At $3 \mathrm{~km}$ distance it becomes approximately one fourth of the annual dose limit. People within $1 \mathrm{~km}$ radius will be underthe threat of radiation crossing the limit. In case of ${ }^{95} \mathrm{Nb}$ (Figure.1) the dose is approximately 18 times larger than the normal limit (1mSv/year). Again the dose value becomes less than $1 \mathrm{mSv}$ at a point, which lies in between $1 \mathrm{~km}$ and $2 \mathrm{~km}$. 


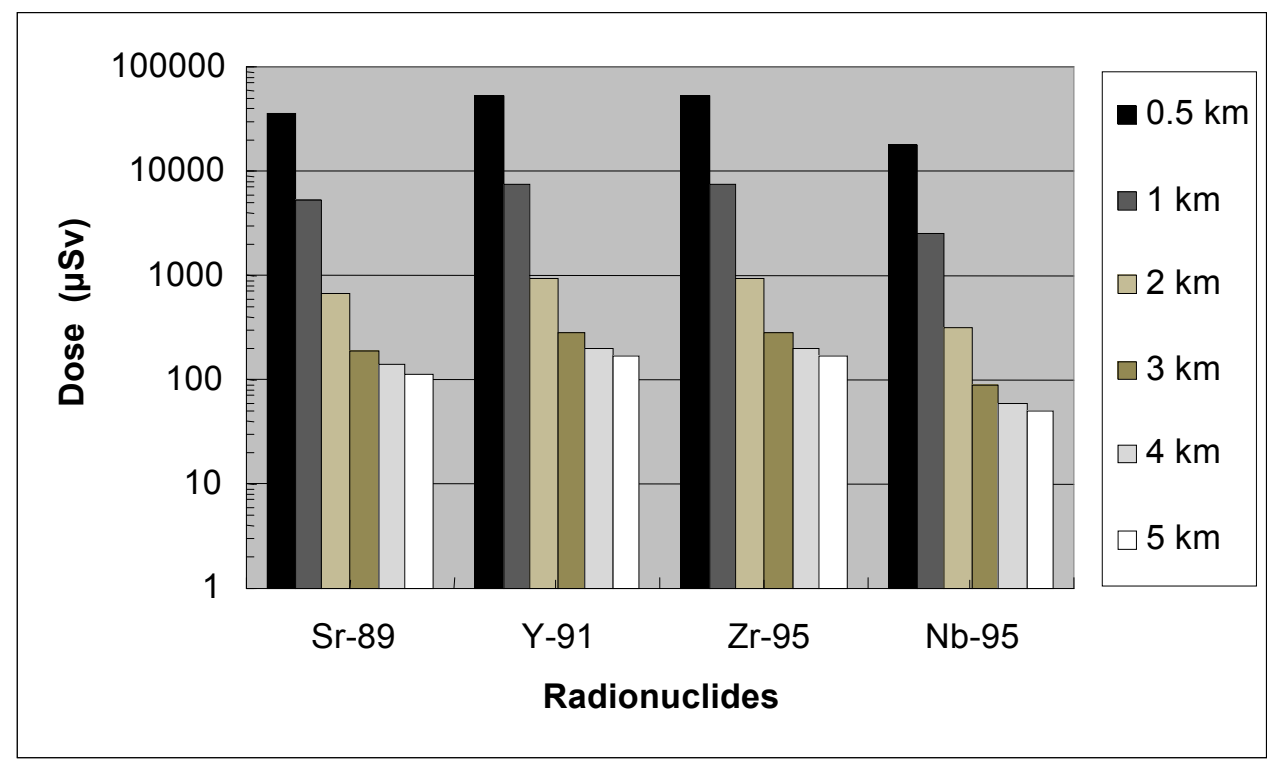

Fig. 1: Lung dose for ${ }^{89} \mathrm{Sr},{ }^{91} \mathrm{Y},{ }^{95} \mathrm{Zr}$ and ${ }^{95} \mathrm{Nbalong} \mathrm{NE}$ direction for $1 \mathrm{~km}$ distance

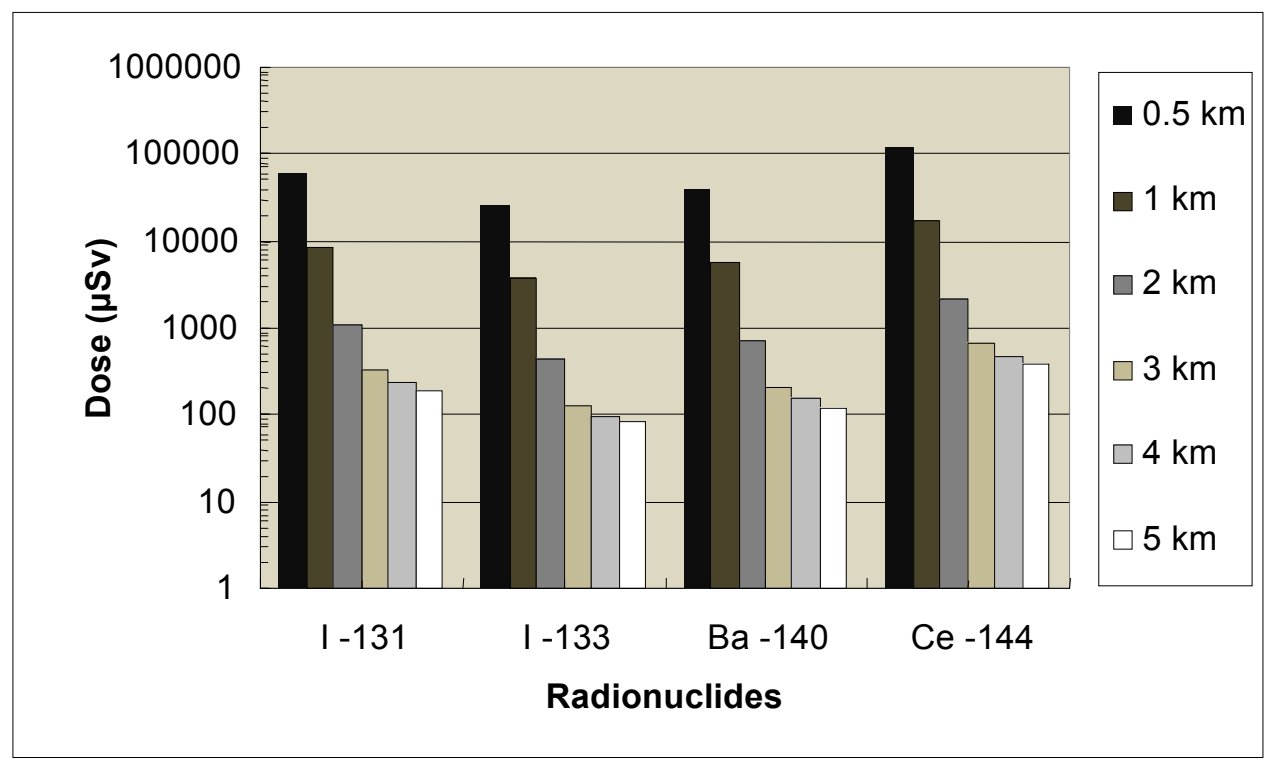

Fig. 2: Lung dose for ${ }^{131,133} \mathrm{I},{ }^{140} \mathrm{Ba}$ and ${ }^{144} \mathrm{Ce}$ along $\mathrm{NE}$ direction for $2 \mathrm{~km}$ distance

When radiation effect from ${ }^{131} \mathrm{I}$ is considered, people are not safe within distanceof $2 \mathrm{~km}$ radius (Figure. 2). The dose from the radionuclide ${ }^{140} \mathrm{Ba}$ is 38 times larger than the annual limit (Figure. 2) at a distance $0.5 \mathrm{~km}$. The safe limit lies at a point in between $1 \mathrm{~km}$ and $2 \mathrm{~km}$. It's safe limits for the radionuclide ${ }^{144} \mathrm{Ce}$ starts at a point that lies beyond $2 \mathrm{~km}$. The radionuclide ${ }^{144} \mathrm{Ce}$ is the most hazardous amongst all the radionuclides discussed in Figures 1 and 2.

It is marked that dose is maximum along North East (NE) direction for all the distances and for all types of radionuclides. This is because wind speed is minimum in this direction, due to which the 
radiation can get a chance to prevail for a longer time in the atmosphere along the direction thus ensuring its higher dose values. The dose variation in the lungs for the above-mentioned radionuclides is expressed through the following inequalities

$$
{ }^{144} \mathrm{Ce}>{ }^{131} \mathrm{I}>{ }^{91} \mathrm{Y}>{ }^{95} \mathrm{Zr}>{ }^{40} \mathrm{Ba}>{ }^{89} \mathrm{Sr}>{ }^{133} \mathrm{I}>{ }^{95} \mathrm{~N}
$$

\section{CONCLUSION}

Radiation doses for lungs have been calculated based on the activity concentrations due to different radionuclides such as, ${ }^{89} \mathrm{Sr},{ }^{91} \mathrm{Y},{ }^{95} \mathrm{Zr},{ }^{95} \mathrm{Nb},{ }^{131} \mathrm{I},{ }^{133} \mathrm{I},{ }^{140} \mathrm{Ba}$ and ${ }^{144} \mathrm{Ce}$ for différent radial distances and direction by using in-house developed computer program «RaDARRA».Of all these radionuclides the maximum and minimum dose contribution mainly come from ${ }^{144} \mathrm{Ce}(30 \%)$ and ${ }^{95} \mathrm{Nb}(4.43 \%)$. It is marked that dose is maximum along North East (NE) direction for all the distances and for all types of the radioisotopes. Methodology used in the present study can" also be utilized for any type of severe accident and any type of reactor power for estimating radiation doses for different organs for radiation protection purpose.

\section{REFERENCES}

1. International Atomic Energy Agency, Safety of Nuclear Power Plants: Design, IAEA Safety Standards Series No. NS-R-1, IAEA, Vienna; 2000.

2. International Atomic Energy Agency, Guidelines for the Review of Accident Management Programmes in Nuclear Power Plants, IAEA Services Series No. 9, IAEA, Vienna; 2003.

3. T. Haste, "Degraded Core Quench: A Status Report", November 1995, NEA/CSNI/R(96)14, OCDE/GD(97)5, OECD/NEA, Paris;1996.

4. G. Bandini, "Molten Material Relocation to the Lower Plenum: A Status Report", September 1998, NEA/CSNI/R(97)34, OECD/NEA, Paris; 1998.

5. European Commission, "Fission Product Release, State-of-the-Art Review", EUR 16499 EN, EC, Luxembourg ;1995.

6. "Overview of the EC Severe Accident Projects", Cooperative Severe Accident Research Program (CSARP), NRC, Bethesda, MD; 2000.

7. W.L. Woodruff, "Radiological Consequence Analysis", RERTR Program, Argonne National Laboratory, Argonne, Illinois, United States of America.

8. U. S. Nuclear Regulatory Commission, "An Atmospheric Dispersion Models for Potential Accident Consequence Assessments at Nuclear Power Plants," Regulatory Guide 1.145; 1979.

9. Md. Moniruzzaman Khan, Assessment of radiological health hazard due to severe accident of nuclear power reactor, Ph. D. Thesis, JU, July 2011. 